\section{Congenital disorders of glycosylation: other causes of ichthyosis}

\author{
European Journal of Human Genetics (2014) 22, 444;
} doi:10.1038/ejhg.2013.168; published online 31 July 2013

We read with interest the comprehensive review by Schmuth et $a l^{1}$ on inherited ichthyoses/generalized Mendelian disorders of cornification. We would like to point out that some congenital disorders of glycosylation (CDG) present ichthyosis. Associations have been described for MPDU1-CDG (formerly CDG-If), DOLK-CDG (CDG-Im), SRD5A3-CDG (CDG-Iq) and PIGL-CDG (CHIME syndrome, Zunich neuroectodermal syndrome). MPDU1-CDG is a defect in the N-glycan assembly in the endoplasmic reticulum (ER). The four reported patients showed skin involvement (ichthyosis and/ or erythroderma). Other features included psychomotor retardation, seizures, hypotonia, gastrointestinal problems, visual impairment, dwarfism and transient growth hormone deficiency. The MPDU1 protein is considered to be a chaperone favoring the efficient utilization of dolicholphosphoglucose and dolicholphosphomannose in glycosylation. A reduced level of the glycosylphosphatidylinositol (GPI)-anchor CD59 has been found in these patients suggesting that they have also a deficiency in GPI-anchor biosynthesis (see PIGLCDG). ${ }^{2,3}$ DOLK-CDG is a defect in dolichol kinase, the last step of the dolichol phosphate biosynthesis. It shows a clinical spectrum with at one end a non-syndromic dilated cardiomyopathy (reported in nine patients), ${ }^{4}$ and at the other end a severe syndrome (reported in four patients) with ichthyosis, as well as dilated cardiomyopathy, epilepsy, microcephaly, visual impairment, hypoglycemia and death within the first 6 months. ${ }^{5}$ SRD5A3-CDG is a defect in polyprenol reductase, involved in the biosynthesis of dolichol. This cerebrocerebello-oculo-cutaneous syndrome has been described in some
15 patients. Its skin component consists of ichthyosis, erythroderma and/or dry skin. ${ }^{6,7}$ PIGL-CDG or CHIME syndrome is characterized by colobomas, congenital heart defects, early-onset migratory ichthyosiform dermatosis, mental retardation and ear anomalies, besides other clinical manifestations. This is a defect in an ER-localized enzyme that catalyzes the second step of GPI-anchor biosynthesis, the de- $\mathrm{N}$-acetylation of $\mathrm{N}$-acetylglucosaminylphosphatidylinositol that occurs on the cytoplasmic side of the ER. It has been reported in eight patients. ${ }^{8}$

The two dolichol phosphate synthesis disorders and MPDU1-CDG can be picked up by serum transferrin isoelectrofocusing. Therefore, we strongly recommend to perform this test in any patient with syndromic ichthyosis or with a syndromic ichthyosis-like skin disorder.

\section{CONFLICT OF INTEREST}

The authors declare no conflict of interest.

Jaak Jaeken ${ }^{\star, 1}$, Daisy Rymen ${ }^{1,2}$ and Gert Matthijs ${ }^{2}$ ${ }^{1}$ Center for Metabolic Disease, KULeuven, Leuven, Belgium; ${ }^{2}$ Center for Human Genetics, KULeuven, Leuven, Belgium E-mail: jaak.jaeken@uzleuven.be

1 Schmuth M, Martinz V, Janecke AR et al: Inherited ichthyoses/generalized Mendelian disorders of cornification. Eur J Hum Genet 2013; 21: 123-133.

2 Kranz C, Denecke J, Lehrman MA et al: A mutation in the MPDU1 gene causes congenital disorder of glycosylation type If (CDG-If). J Clin Invest 2001; 108: 1613-1619.

3 Schenk B, Imbach T, Frank CG et al: MPDU1 mutations underly a novel human congenital disorder of glycosylation, designated type If. J Clin Invest 2001; 108 1687-1695.

4 Kranz C, Jungeblut C, Denecke J et al: A defect in dolichol phosphate biosynthesis causes a new inherited disorder with death in early infancy. Am J Hum Genet 2007; 80: 433-440.

5 Lefeber DJ, de Brouwer AP, Morava E et al: Autosomal recessive dilated cardiomyopathy due to DOLK mutations results from abnormal dystroglycan O-mannosylation. PLOS Genet 2012; 7: e1002427.

6 Al-Gazali L, Hertecant J, Algawi K, El Teraifi H, Dattani M: A new autosomal recessive syndrome of ocular colobomas, ichthyosis, brain malformations and endocrine abnormalities in an inbred Emirati family. Am J Med Genet A 2008; 146: 813-819.

7 Cantagrel V, Lefeber DJ, Ng BG et al: SRD5A3 is required for converting polyprenol to dolichol and is mutated in a congenital glycosylation disorder. Cell 2010; 142: 203-217.

8 Ng BG, Hackmann K, Jones MA et al: Mutations in the glycosylphosphatidylinositol gene PIGL cause CHIME syndrome. Am J Hum Genet 2012; 90: 685-688. 